\title{
ARTE RUPESTRE DE ESTILO PALEOLÍTICO DEL PORTALÓN DE CUEVA MAYOR DE LA SIERRA DE ATAPUERCA (IBEAS DE JUARROS, BURGOS): ¿CRONOLOGÍA PALEOLÍTICA O CONTEMPORÁNEA?
}

\author{
THE ROCK ART OF PALAEOLITHIC STYLE IN THE PORTALON OF CUEVA MAYOR \\ IN THE SIERRA DE ATAPUERCA (IBEAS DE JUARROS, BURGOS): PALAEOLITHIC \\ OR CONTEMPORARY CHRONOLOGY?
}

MARCOS GARCÍA $(*)$

ANA ISABEL ORTEGA $(* *)$

MIGUEL ÁNGEL MARTÍN $(* * *)$

POLICARP HORTOLÀ $(* * * *)$

MARÍA CRUZ ZULUAGA $(* * * * *)$

\section{RESUMEN}

Las dudas manifiestas en las diversas referencias bibliográficas en torno a la cronología del motivo pintado existente en el Portalón de Cueva Mayor llevaron a la revisión del mismo. Se planteó un protocolo de análisis donde se atendiera a cuestiones historiográficas, contextuales y gráficas. Los resultados del trabajo cuestionan la asignación a momentos paleolíticos de la grafía, planteando, de manera contraria, que la ejecución fue llevada a cabo a inicios del presente siglo.

\footnotetext{
ABSTRACT

The doubts shown in different papers on the chronology of the motif painted in the Portalón of Cueva Mayor have caused its revision. A form of analysis is proposed where-

(*) Dpto. de Geografía, Prehistoria y Arqueología. Universidad del País Vasco. Tomás y Valiente s/n. 01006 Vitoria. Correo electrónico: marcosgarcia@inicia.es

(**) Dpto. de Ciencias Históricas y Geografía. Facultad de Humanidades y Educación. Universidad de Burgos. Carretera Villadiego s/n. 09001 Burgos. Correo electrónico: mammaiom@ teleline.es

$(* * *)$ Grupo Espeleológico Edelweiss. Excma. Diputación Provincial de Burgos. 09071 Burgos. Correo electrónico: mammaiom@teleline.es

(****) Laboratorio de Arqueología. Universidad Rovira i Virgili. Plaza Imperial Tarraco 1. 43005 Tarragona. Correo electrónico: policarp@romani.iuz.urv.es

(*****) Departamento de Mineralogía y Petrología. Facultad de Ciencias Geológicas. Universidad del País Vasco. Campus de Lejona (Vizcaya). Correo electrónico: noozuibm@lg.ehu.es El artículo fue remitido en su versión final el $26-\mathrm{V}-2000$
}

by we pay attention to bibliographic, contextual and graphical questions. The results of the work question the assignment to the Paleolithic of the design; on the contrary we propose that the motif was painted at the beginning of the last century.

Palabras clave: Arte rupestre. Autentificación. Sierra de Atapuerca. Estudio de materiales colorantes.Arqueometría.

Key words: Rock art. Authenticity. Sierra de Atapuerca. Study of the colouring material. Archaeometry.

\section{LOCALIZACIÓN}

El karst de la Sierra de Atapuerca se localiza a unos $15 \mathrm{~km}$ al Este de la ciudad de Burgos (Fig. 1). Corresponde a una pequeña elevación, sensiblemente horizontal, que presenta sus mayores cotas en las cumbres del Matagrande y San Vicente con 1079 y 1081 m.s.n.m, respectivamente. Constituye la estribación más noroccidental del Sistema Ibérico, en una zona de enlace entre las depresiones terciarias de las Cuencas del Duero y del Ebro y las estribaciones meridionales de la Cordillera Cantábrica, conocida como Corredor de la Bureba o Estrecho de Burgos. Los sedimentos de este enclave contienen una de las muestras arqueo-paleontológicas más destacadas del Pleistoceno inferior y medio. 


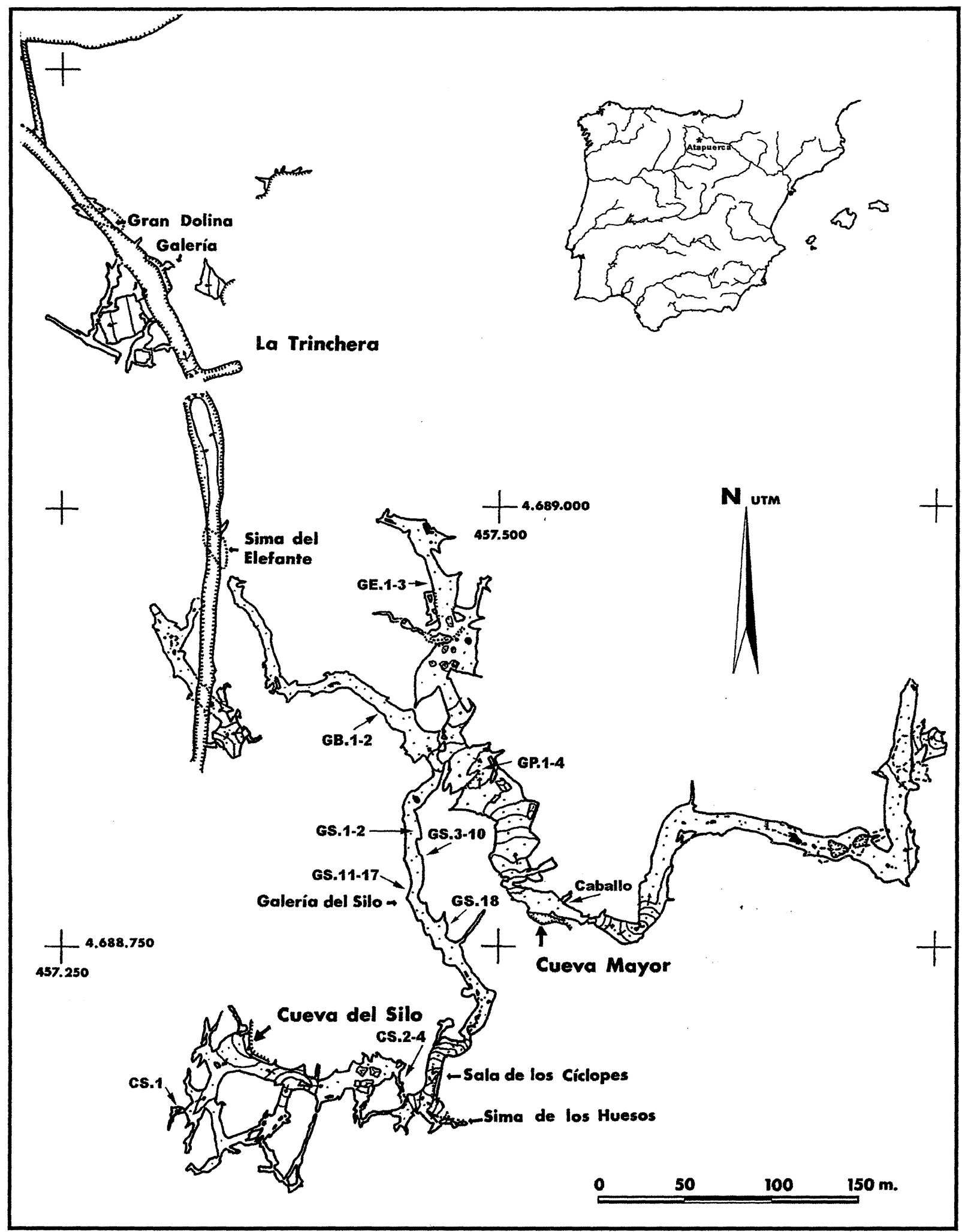

Fig. 1. Localización de la Sierra de Atapuerca (Ibeas de Juarros-Atapuerca, Burgos) en la Península Ibérica y situación de los yacimentos en el karst. Topografía Grupo Espeleológico Edelweiss.

T. P., 58, n. $^{\circ} 1,2001$ 


\section{HISTORIA DE LAS INVESTIGACIONES}

La primera referencia escrita relativa a evidencias arqueológicas en las cavidades de la Sierra de Atapuerca data del 20 de mayo 1863, dando a conocer un conjunto de restos arqueológicos, principalmente restos óseos humanos, de Cueva Ciega, publicada en el periódico El Eco Burgalés por Felipe de Ariño y Ramón Inclán (Sampayo y Zuaznávar, 1868: 17).

En 1868 los ingenieros de minas Pedro Sampayo y Mariano Zuaznávar publican el libro Descripción con planos de la Cueva llamada deAtapuerca, ilustrado con vistas de Isidro Gil, en el que describen el entorno y la cavidad, incluyendo además unas precisas topografías de planta y perfiles. En él señalan la existencia de "varios trozos de barro cocido" en la entrada de la cueva. También citan la presencia de numerosas inscripciones, atribuyendo las más antiguas al siglo XIII, si bien aluden a otra con caracteres posiblemente árabes. El tratamiento monográfico del estudio de una caverna hace que pueda ser considerado como el primer trabajo espeleológico publicado en la Península Ibérica.

La difusión de esta publicación motivó que especialistas de distintas disciplinas se interesasen por la Cueva de Atapuerca, siendo así incluida en el catálogo Cavernas y Simas de España (Puig y Larraz, 1896: 72-73).

El primero que señala, gracias a las indicaciones del guía de la cueva, la presencia de varios grabados es L. March (1906), apuntando la existencia de un motivo soliforme y otro lunar de probable cronología prehistórica.

En agosto de 1910 el médico y el farmacéutico de Ibeas de Juarros señalan las dos visitas realizadas por J. Carballo, en su compañía, el mes anterior a la Cueva de Atapuerca, anticipando parcialmente en la prensa local los descubrimientos realizados por el citado investigador (Ruiz y Martínez, 1910). Meses después, el propio J. Carballo (1910) apunta la existencia de restos arqueológicos en la rampa exterior de acceso a la cavidad, así como en su vestíbulo, actualmente llamado Portalón, y rampa interior. También describe la cabeza de caballo pintada en rojo del Portalón, a la que no presta mucha credibilidad. En el interior de la cueva publica la existencia de posibles caracteres visigóticos y árabes, así como "una raya vertical de unos 90 centímetros, cruzada por varios trazos paralelos" (Carballo, 1910: 478) en rojo en la Galería del Silo y diversos surcos grabados en una lateral de la Galería de las
Estatuas, que interpreta, al igual que el citado L. March, como símbolos astronómicos.

Años más tarde H. Breuil y H. Obermaier (1913: 5-6) revisan los motivos publicados anteriormente por Carballo: desmienten los signos astronómicos que identifican como morfologías de fósiles, describen como oso la cabeza de caballo y señalan la existencia de nuevos motivos pintados junto a la figura roja de la Galería del Silo. A su vez se publican nuevas representaciones: figuras geométricas en rojo sobre un bloque del Salón del Coro (Galería Principal), un zig-zag grabado en la Galería de las Estatuas y un panel de grabados en la Cueva del Silo (Breuil, 1920: 329-333, 1934: 36-37, 1952: 391). Los materiales arqueológicos del Portalón los encuadran en momentos neolíticos o eneolíticos.

Vuelven a encontrarse referencias a Cueva Mayor en el trabajo Terciario Continental de Burgos, así como la primera cita sobre los rellenos de Trinchera (Royo y Gómez, 1926: 64-66), aunque sin advertir la presencia de los restos fosilíferos en los mismos. Por esas mismas fechas Martínez SantaOlalla (1925: 89-90, 1926: 168-169, 1930: 113114) se refiere nuevamente a las representaciones gráficas y estudia los restos cerámicos aparecidos en Cueva Mayor.

Habrá que esperar hasta 1954 para que el Grupo Espeleológico Edelweiss (G.E.E.) emprenda la catalogación y estudio de las cavidades (Martín et alii, 1981). En 1962 localizan restos de fauna enTrinchera, donde un año después B. Osaba (1965: 126-128) descubre un bifaz, excavando en 1964 el yacimiento F. Jordá (1965: 149), quien reconoce ocupaciones humanas de momentos achelenses. En 1966 dicho investigador excava en el Portalón de Cueva Mayor. En 1970 el G.E.E. descubre en el abrigo del Mirador diversos restos arqueológicos que entrega en el Museo de Burgos (Osaba, 1979: 79).

En 1972 G.A. Clark (1979: 89-119) realiza trabajos arqueológicos en los diferentes yacimientos de Trinchera y Cueva Mayor. Ese mismo año el G.E.E descubre la Galería del Sílex, espacio que contiene gran número de paneles con pinturas y grabados atribuibles a momentos post-paleolíticos. Ambos hechos motivaron el inicio en 1973 del programa de excavaciones y documentación de arte rupestre por parte de J.M.Apellániz, prolongándose hasta 1983 (Apellániz y Uribarri, 1976; Apellániz y Domingo, 1987). Otros motivos grabados, hasta la actualidad inéditos, han sido descubiertos en diferentes galerías de Cueva Mayor y Cueva del Silo.

En 1976 T. Torres excava los yacimientos de 
Trinchera y, por indicación del G.E.E, la Sima de los Huesos de Cueva Mayor, donde se localizan los primeros restos humanos pleistocenos (Aguirre $e t$ alii, 1976) que darían lugar al inicio del proyecto interdisciplinar dirigido por E. Aguirre desde 1978 (Aguirre et alii, 1987) y continuado, desde 1991, por J.L. Arsuaga, J.M. Bermúdez de Castro y E. Carbonell (Bermúdez et alii, 1999: 17-22).

\section{LA CABEZA PINTADA DEL PORTALÓN DE CUEVA MAYOR}

\section{La polémica sobre su descubrimiento}

El reconocimiento de la autoría del descubrimiento del arte rupestre de Atapuerca propició en los primeros años una polémica donde se incluyeron descalificaciones entre H. Breuil y J. Carballo. Lo cierto es que la primera publicación de carácter científico se debe a J. Carballo (1910), quien realizó una visita en el mes de julio de 1910.

H. Breuil y H. Obermaier llevaron a cabo una visita a la cueva el 29 de febrero de 1912 como consecuencia, según el primero de ellos (Breuil, 1934: 36), de una carta remitida por H.Alcalde del Río el 2 de junio de 1910 (Breuil, 1920: 329, 1934: 36) donde les indicaba la existencia de una cabeza de animal, de diversos signos rojos de estilo paleolítico cantábrico y de grabados geométricos neolíticos o más recientes (especialmente en la Cueva del Silo).

En la primera edición delHombre Fósil, H. Obermaier (1916: 231), dentro del capítulo dedicado al arte, señala como descubridor a H.Alcalde del Río. Sin embargo, en la fe de erratas (Obermaier, 1916: 353) indica que allí donde se leía Alcalde del Río léase J. Carballo, anotación que fue corregida en la segunda edición, con lo que parece claro que al menos Obermaier (1925: 263) desmintió expresamente el presunto descubrimiento deAlcalde del Río.

Como respuesta al artículo de H. Breuil de 1920, J. Carballo (1920: 138-140) replica de forma tajante reivindicando su autoría del descubrimiento y que la primera publicación correspondía al farmaceútico y médico de Ibeas. En esta última se mencionan (Ruiz y Martínez, 1910) dos visitas del P. Carballo en el mes de julio a la cueva, la primera a la ida hacia Santo Domingo de Silos y la segunda, de dos días de duración, a la vuelta de su estancia en Silos, el día 22, aunque Carballo sólo se refiere en su réplica a una visita de dos horas de duración, realizada además en condiciones precarias de salud (Carballo, 1921: 139-140) (1).

Ante la controvertida situación que se estaba creando, Breuil (1921: 270-271) remite una carta al Consejo del Boletín de la Real Sociedad Española de Historia Natural, leyéndose ésta en la sesión ordinaria del 6 de julio de 1921. En la misma descalifica científicamente a J. Carballo y expone la escasa credibilidad de sus palabras, reafirmando la sinceridad de H. Alcalde del Río.

La polémica quedaría olvidada a partir de este momento. Solamente Breuil (1952: 391) se referirá al hecho, sin echar más leña al fuego, en su obra de síntesis sobre el arte rupestre paleolítico.

\section{La asignación taxonómica}

La figura del Portalón ha recibido una asignación taxonómica variable entre caballo y oso. J. Carballo.(1910: 472) se refirió a ella como cabeza de caballo pintada en color ocre. Dicha opinión fue compartida por J. Cabré (1915: 119) y J. Royo y Gómez (1926: 64). Dentro de este razonamiento B. Melén$\operatorname{dez}(1956: 279)$, desde un punto de vista paleobiológico, matiza la asignación señalando su pertenencia al Equus asinus.

La interpretación de oso fue propuesta, con interrogantes, por Breuil y Obermaier (1913: 6). Dicho posicionamiento fue mantenido años después por Breuil (1920: 331, 1952: 391) y Martínez Santa-Olalla (1925: 168).

M.Almagro (1947: 364) llega a considerar, probablemente por desconocimiento directo de la grafía, las referencias como diferentes motivos: "donde hay pintada una cabeza de oso y signos tectiformes, y una tosca cabeza de caballo tallada en las paredes de la roca en alto relieve y pintada". La confusión encuentra su explicación en la fotografía presentada por el autor. En el interior de la presunta cabeza de oso, Almagro ve una cabeza de caballo que se compone de la línea frontal y parte de la zona naso-frontal de la anterior figura y de una grieta situada en la mitad de la cara que se constituye como línea maxilar, a la vez que se suma otra ortogonal a la anterior constituyendo el cuello. En ambos casos

(1) Por extraño que parezca, en el artículo de prensa no se hace referencia alguna a la existencia de la figura pintada del Portalón ni a las de la Galería del Silo, aunque sí que se citan las restantes evidencias arqueológicas descubiertas por el P. Carballo, incluidos los supuestos signos astronómicos grabados, ya aludidos por L. March en 1906.

T. P., 58, n. ${ }^{\circ} 1,2001$ 
son líneas de fractura del soporte que dependiendo de la iluminación se acentúan configurando la figura descrita, es decir, un caballo en el que se combina lo pintado con lo presuntamente esculpido.

F. Jordá (1964: 68) mantendrá dicha propuesta en un primer momento, si bien años más tarde (Jordá, 1985: 311) señalará la existencia de una sola cabeza de caballo. Es probable que la rectificación venga dada por el conocimiento directo que tuvo el investigador del lugar, y no bibliográfico como ocurriera en la primera publicación que se incluye dentro de un libro de actas de la reunión sobre arte celebrada en Wartenstein en 1960.

Para nosotros, al igual que para la mayoría de los autores que la han citado posteriormente con o sin conocimiento directo, se trata de una figura de équido. Morfológicamente se trata de una cabeza ancha y con las orejas adelantadas, que en algún momento puede recordar la silueta, tal y como señaló Meléndez, de un asno.

\section{Localización y descripción de la pintura}

La pintura objeto de estudio se encuentra en el Portalón de Cueva Mayor, también conocida como Cueva deAtapuerca, en la pared localizada frente a la entrada de la cueva. El soporte es una caliza de edadTuroniense medio-superior - Coniaciense frecuentemente dolomitizada (I.T.G.E, 1997). El análisis emprendido mediante difracción de rayos $\mathrm{X}$ indica que está compuesta mayoritariamente por calcita, aunque también se han detectado otros minerales en cantidades menores como el cuarzo y la moscovita. Morfológicamente se caracteriza por ser irregular, producto de la fragmentación a la que se ve sometida la pared debido a los cambios climáticos del exterior.

La evidencia gráfica se concreta en una representación figurativa zoomorfa donde el formato utilizado se refiere a un prótomo de équido (Lám. I) que presenta una altura (de la zona del ollar hasta el arranque del cuello) de $66 \mathrm{~cm}$ y una anchura de 41 $\mathrm{cm}$ (de la zona anterior a las orejas, donde se localizaría el tupé hasta el contacto de la línea maxilar con la del pecho). En las fotografías que presentan H. Breuil y H. Obermaier (1913: 5, fig. 3) y M.Almagro (1947: 373, fig. 293) puede reconocerse perfectamente el diseño del pecho, hoy en día imperceptible. Las partes anatómicas representadas son el inicio del cuello, línea maxilar, boca, línea frontal, orejas, arranque del cuello y ojo.

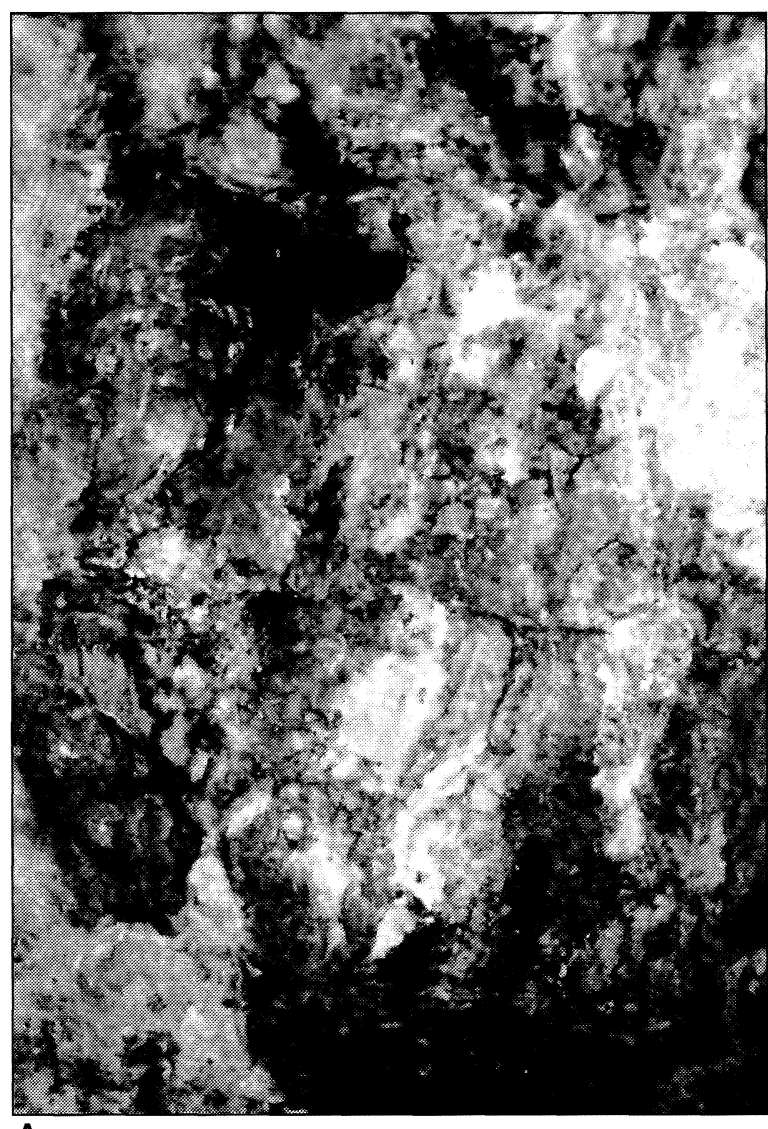

A

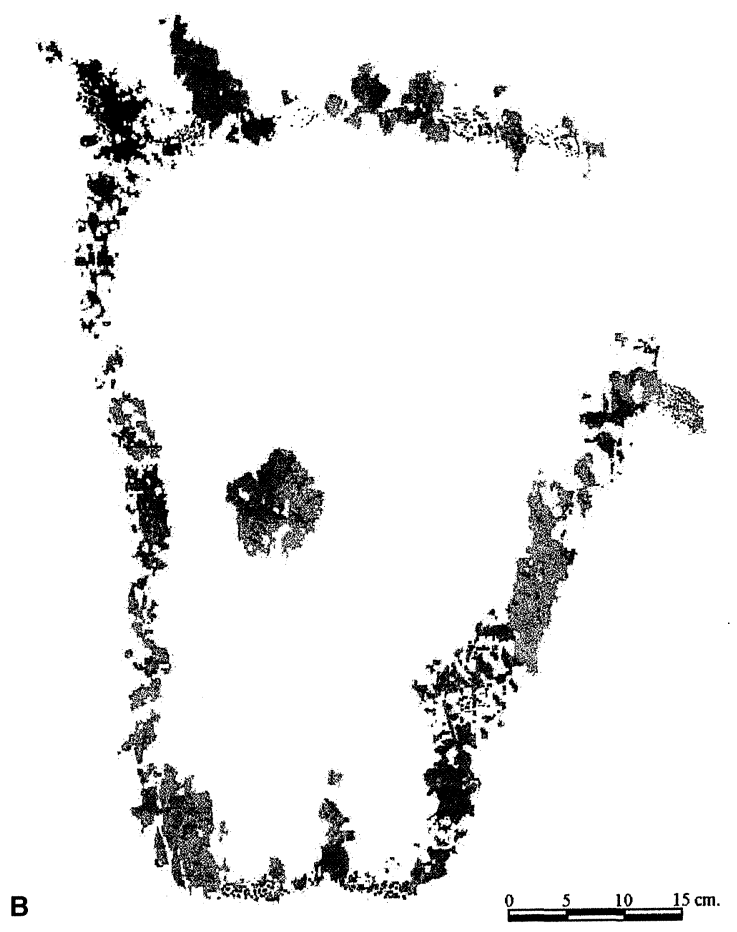

Lám. I. Fotografía (A) y calco (B) del prótomo de caballo. 
La modulación y el grosor de la línea de contorno son utilizados como recursos de representación, transmitiendo indirectamente elementos anatómicos del animal. Así, la región zigomática-maxilar, o carrillos, se consigue destacar por la ampliación del grosor de la línea y por una suave sinuosidad de la línea maxilar. De forma similar, si bien recurriendo de manera exclusiva a la ampliación del grosor de la línea, viene a representarse la zona del ollar.

El medio y modo de aplicación de la pintura no ha podido ser estudiado debido al mal estado de conservación.

\section{Estudio de los materiales colorantes}

Con el fin de caracterizar los materiales colorantes utilizados han sido obtenidas un total de cuatro muestras: dos de la figura zoomorfa y dos del soporte. Éstas han sido recogidas mediante cuchillas estériles Swann-Morton $\mathrm{n}^{\circ} 15$ montadas en un escalpelo. Cada una de las muestras ha sido introducida en un tubo de ensayo esterilizado, intentando evitar de este modo contaminaciones que pudieran generarse durante el proceso de extracción.

\section{A. Estudio de componentes minerales}

Para el estudio de componentes minerales han sido analizadas dos muestras del soporte y una de la figura zoomorfa. Los métodos analíticos empleados han sido la difracción de rayos X (D.R.X.) (2) y la Microscopía Electrónica de Barrido (M.E.B.) equipada con un microanalizador de EDS (espectroscopía de separación de energías de rayos X) (3).

(2) Los estudios de difracción de rayos $\mathrm{X}$ se han realizado con un equipo PHILIPS PW-1710 equipado con anticátodo de $\mathrm{Cu}$, goniómetro vertical, rendija automática, monocromador de grafito, unidad de control automatizada e intercambiador de muestras. Estos estudios se han llevado a cabo en el Servicio de Recursos Científicos de la Universidad Rovira i Virgili. Las condiciones instrumentales empleadas han sido las estándar de $\mathrm{V}=40 \mathrm{kV}, \mathrm{I}=20 \mathrm{~mA}$, y la región explorada $5-66^{\circ} 2 \theta$.

(3) Mediante la microscopía electrónica de barrido se ha efectuado tanto un estudio morfológico de la muestra correspondiente a la figura zoomorfa como el microanálisis de las muestras. Para la figura zoomorfa se han utilizado microscopios modelo JEOL JSM-6400, con filamento de wolframio, de la Facultad de Ciencias de la Universidad del País Vasco y del Servicio de Recursos Científicos de la Universidad Rovira i Virgili. Se han empleado condiciones de trabajo estándar: una tensión de aceleración de $20 \mathrm{kV}$ y una intensidad de corriente comprendida entre 6.10-11 y 10-10 A. El microanálisis se ha llevado a cabo con un microanalizador EDAX DX4I unido a un M.E.B. Philips XL30 con filamento de La. La utilización de las técnicas de M.E.B. y EDX-S exigen inicialmente que las muestras sean convertidas en

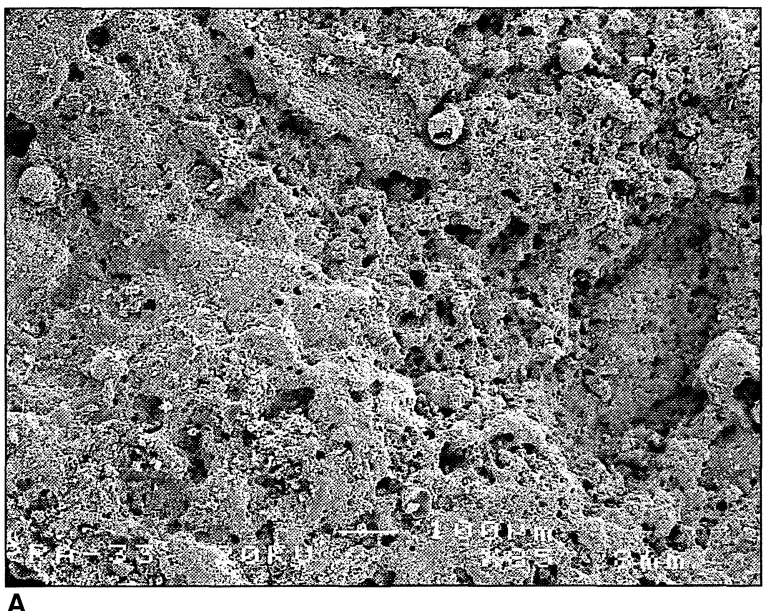

A

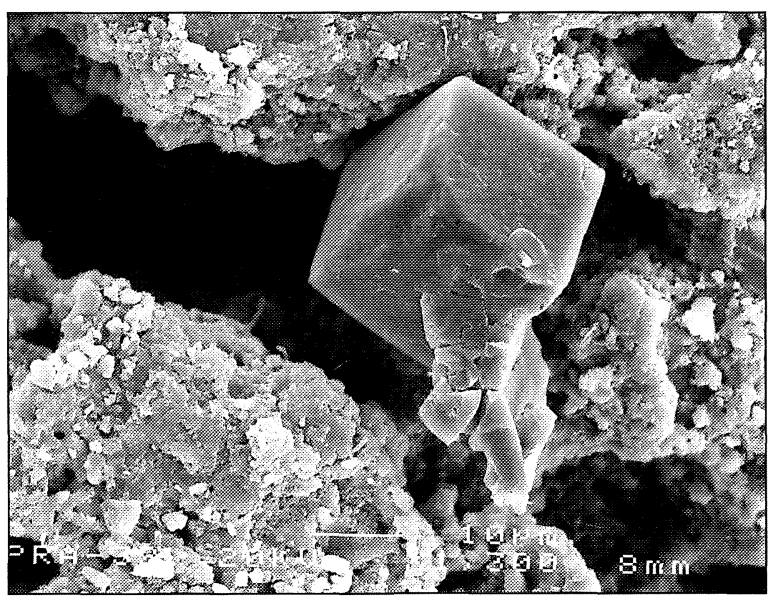

Lám. II. Fotografías del M.E.B. de la materia colorante: aspecto general de la superficie (A) y detalle de un cristal de calcita $(\mathrm{B})$.

No obstante, en el primer procedimiento es preciso tener en cuenta las limitaciones propias del método. Por un lado, para una buena identificación es necesario disponer de muestra suficiente para el análisis, de manera que la zona irradiada corresponda únicamente a la muestra objeto de estudio y se evite la presencia de picos de difracción correspondientes al material en que está construido el portamuestras. Asimismo, la detección de ciertos minerales es difícil en muestras de composiciones

buenos conductores eléctricos. De esta manera se consigue una buena calidad de imagen y se evita que la superficie de la muestra se caliente con el haz electrónico y se produzcan alteraciones durante la observación y el análisis. Para ello han sido recubiertas por una película fina conductora de oro (en el caso de la muestra zoomorfa) y de carbono (en la microanalítica del resto de las muestras) utilizando un equipo BAL-TEC SCD 004 Sputter COATER donde se irradiaron con una corriente de $15 \mathrm{~mA}$ durante 420 segundos, quedando cubiertas con una capa de aproximadamente $55 \mu \mathrm{m}$ de espesor. 


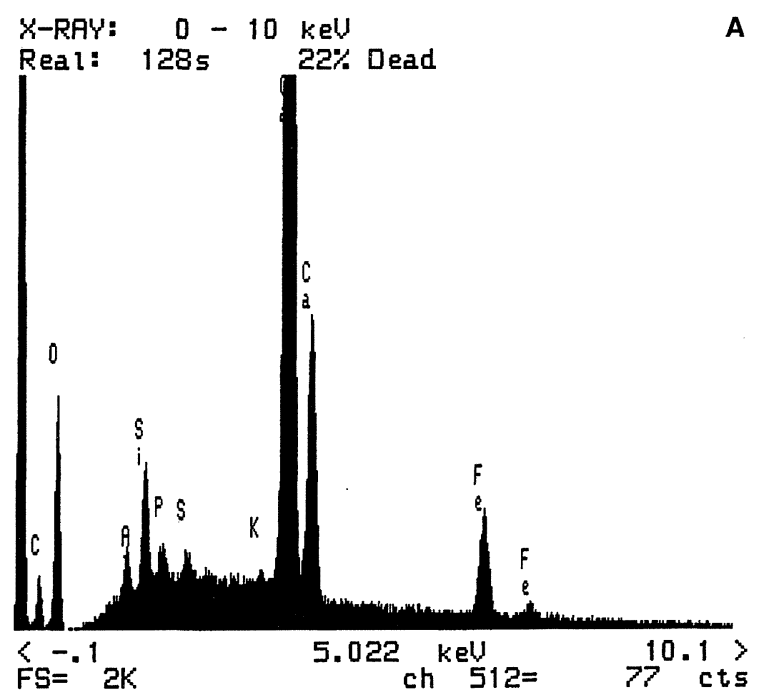

A

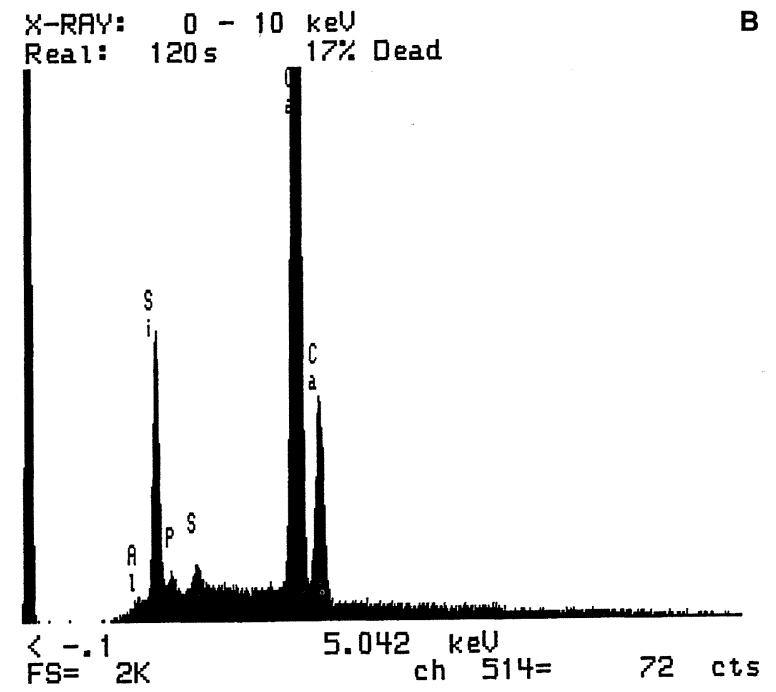

Fig. 2. Espectros del M.E.B. de la materia colorante del prótomo de caballo (A) y del soporte calizo (B).

complejas debido al solapamiento de las señales correspondientes a las diferentes especies. Este problema es aún más importante si se trata de minerales con bajo poder reflectante, en cuyo caso sólo pueden ser identificados si se presentan en cantidades importantes.

Estos problemas se han encontrado en el análisis de la muestra correspondiente a la figura zoomorfa. El fragmento objeto de análisis es muy pequeño, y además la parte correspondiente al soporte es volumétricamente superior al constituyente rojo, lo cual condiciona fuertemente los resultados obtenidos por esta técnica.Así, en el espectro de difracción de rayos $\mathrm{X}$ puede identificarse claramente la calcita como constituyente mayoritario y la presencia de cantidades pequeñas de mica y cuarzo que corresponden al soporte calizo. Sin embargo, no pudo identificarse claramente ninguna otra especie a la que atribuir la coloración rojiza.

En las observaciones al M.E.B la muestra correspondiente a la figura zoomorfa presenta un aspecto microporoso, poros de tamaño medio de $25 \mu \mathrm{m}$, homogéneo (Lám. IIA). Éste es superficial y se debe a la humedad y al agua de percolación que se concentra en las paredes. En una observación más detallada puede apreciarse el aspecto microcristalino que corresponde a rocas carbonatadas como el soporte; así mismo también se aprecia el crecimiento de cristales de hábito romboédrico de unos $20 \mu \mathrm{m}$ que corresponden a la calcita (Lám. IIB). En otros poros se ha observado el crecimiento de pequeños filamentos de naturaleza orgánica atribuibles a microorganismos.
Los microanálisis efectuados muestran la presencia de diferentes elementos procedentes tanto del material colorante como del soporte (Fig. 2), debido a que el haz de análisis tiene una profundidad de penetración de unos $5 \mu \mathrm{m}$. No obstante, mientras que el Ca, Si, Al, Mg y K identificados pueden ser claramente atribuidos al soporte, de acuerdo a su composición mineralógica, el Fe detectado proviene de la sustancia colorante.

En conclusión, las observaciones microscópicas y microanálisis realizados no muestran ninguna característica que indique que la sustancia empleada como colorante rojo sea una sustancia artificial, de hecho apuntan claramente hacia una sustancia natural, un óxido de hierro y más en concreto, probablemente, una hematites.

\section{B. Estudio de los componentes orgánicos}

Para el estudio de los componentes orgánicos, concretamente restos de lípidos y substancias relacionadas, se ha estudiado un fragmento de la figura zoomorfa. El análisis de los lípidos en pinturas y otras obras artísticas es un aspecto de interés en la moderna investigación científico-técnica del Arte, por ejemplo, para la identificación de los aglutinantes de capas pictóricas y determinación de su grado de envejecimiento (Bosch, 1996). El método analítico empleado ha sido la cromatografía de gases seguida de espectrometría de masas (CG/EM), habiéndose escogido tal método dado que su habitual alta sensibilidad favorece el análisis de mate- 


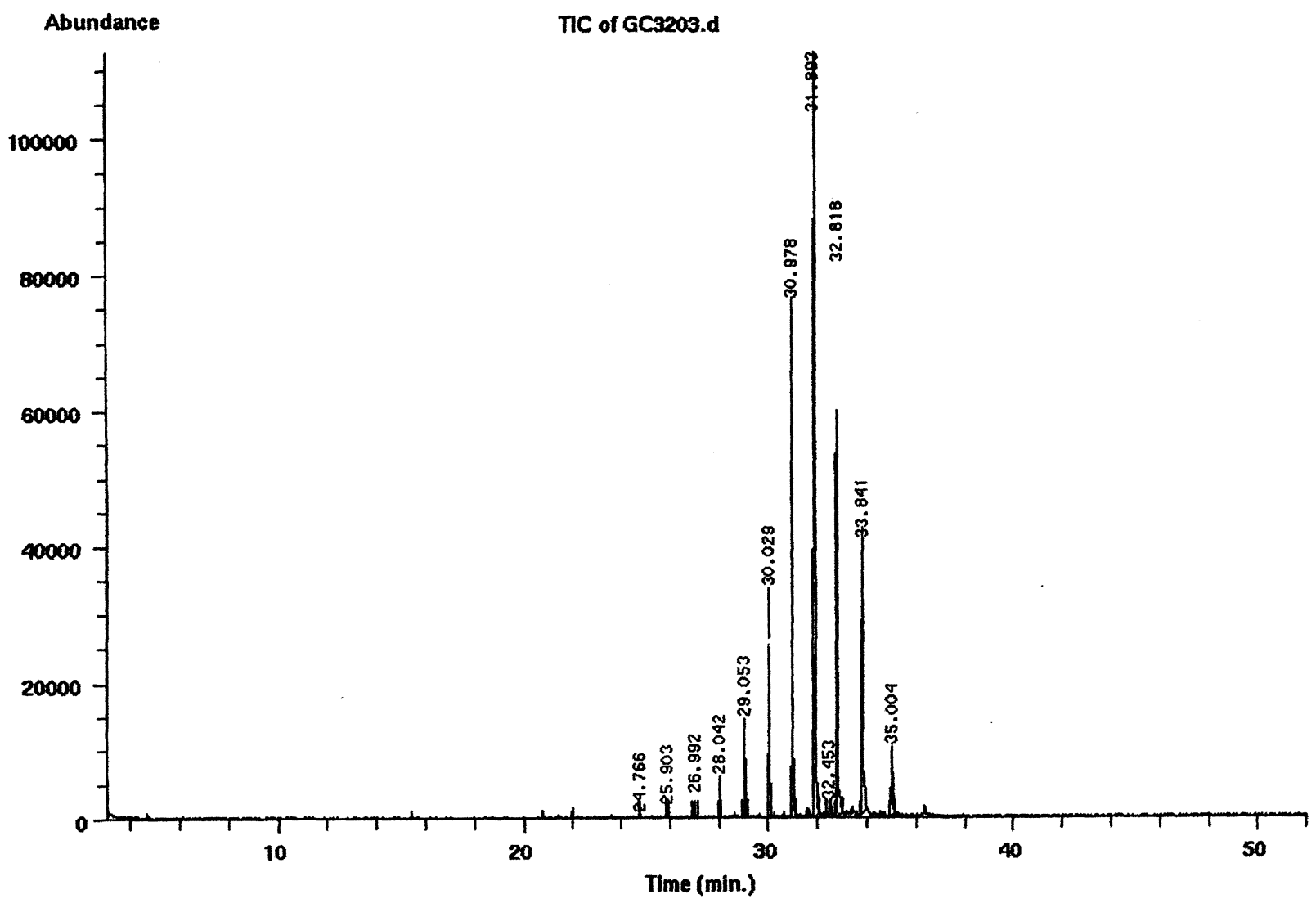

Fig. 3. Cromatograma de la materia colorante del prótomo de caballo.

riales arqueológicos cuando se dispone de poca cantidad de muestra (Evershed, 1993) (4).

En el previo examen microscópico de la superficie de la muestra no se han observado restos evidentes de líquenes. El cromatograma de gases del fragmento de pintura muestra la presencia en la figura zoomorfa de hidrocarburos de cadena larga

(4) En primer lugar se ha llevado a cabo un examen microscópico de la superficie de la muestra mediante lupa binocular a $50 x$. Seguidamente se ha realizado el análisis químico del fragmento mediante el método indicado anteriormente. Dada la ínfima cantidad y poco grosor de capa pictórica disponible, no se ha visto aconsejable realizar ninguna descontaminación de su superficie previa a su análisis químico. La extracción de los compuestos lipídicos de la muestra se ha realizado mediante trituración de la misma, digestión por tres veces con $2 \mathrm{~mL}$ de hexano durante 20 minutos en baño de ultrasonidos, decantación y, finalmente, evaporación. Tras el proceso de extracción, los compuestos han sido separados mediante un cromatógrafo de gases modelo 5890 Serie II (columna capilar de fenil-metil-silicona de $30 \mathrm{~m}$ de longitud por $0.25 \mathrm{~mm}$ de diámetro externo y $0.25 \mu \mathrm{m}$ de diámetro interno, modelo 5), siendo seguidamente analizados mediante un espectrómetro de masas modelo 5989 A (librería de espectros de masas de 54000 compuestos del National Institute of Standards and Technology de los Estados Unidos de América), siendo todos estos instrumentos de la marca Hewlett-Packard. Este análisis se ha llevado a cabo en los Servicios Científico-Técnicos de la Universidad de Barcelona.
$\mathrm{C}_{>21}$ (Fig. 3). La librería de espectros de masas disponible no ha permitido llegar a resultados concluyentes sobre la identidad exacta de los compuestos separados, pero sí se ha podido determinar, de acuerdo con las fragmentaciones iónicas exhibidas, que tales hidrocarburos son de carácter mayoritariamente lineal, sin ramificar y saturado (n-alcanos o hidrocarburos n-parafínicos, $\mathrm{C}_{\mathrm{n}} \mathrm{H}_{2 \mathrm{n}+2}$ ). La presencia de n-alcanos de cadena larga es atribuible a productos de degradación de lípidos de origen no animal. En el ámbito geoquímico, los lípidos biológicos son la fuente principal de hidrocarburos $\mathrm{C}_{>14}$ o sus precursores (Meinschein, 1969) (5).

(5) Los lípidos de las bacterias son particularmente ricos en hidrocarburos $C_{10}-C_{30}$ (Perrodon, 1988). Los lípidos de ceras, resinas, semillas y pólenes de los vegetales superiores contienen especialmente los n-alcanos heptacosano $\left(\mathrm{C}_{27} \mathrm{H}_{56}\right)$, nonacosano $\left(\mathrm{C}_{29} \mathrm{H}_{60}\right)$ y hentriacontano $\left(\mathrm{C}_{31} \mathrm{H}_{64}\right)$ (Brassell et alii, 1978; Perrodon, 1988); en un sentido más amplio, muchos vegetales superiores exhiben una fuerte tendencia a poseer un número impar de $\mathrm{C}$ en sus n-alcanos $C_{>22}$ (Meinschein, 1969). Los lípidos son abundantes en algas, especialmente en la familia del género Botryococcus; en diatomeas pueden constituir hasta el $70 \%$ del peso seco. En algas pardas (feofíceas), verdes (clorofíceas) y rojas (rodofíceas) ha sido aislado el hidrocarburo parafínico hentriaconta- 
En conclusión, asumiendo que los hidrocarburos hallados pueden ser de origen bacteriano, vegetal superior o algal, tal aparición en la muestra se debería, con mayor probabilidad, a contaminación por la presencia de líquenes sobre la pintura.

\section{Identificación de la procedencia del material colorante}

Además de la caracterización del material colorante empleado en la pintura, un óxido de hierro, se emprendió un estudio con el fin de identificar la posible procedencia de dicha sustancia. Así, considerando que Atapuerca está situada en una zona de indicios y explotaciones de hierro, y dada la coloración rojiza que los minerales de este elemento presentan habitualmente, la hipótesis de trabajo más lógica fue considerar que el pigmento rojo de la figura proviene de un mineral de hierro del entorno.

Por ello se estudiaron tres muestras procedentes de explotaciones mineras cercanas: dos de diferentes puntos de Olmos de Atapuerca (en la Sierra de Atapuerca) y una de Barbadillo (pueblo situado en la Sierra de la Demanda). En todos los casos se ha determinado su composición mineralógica por difracción de rayos X, constatándose la presencia de varios minerales de hierro. Mientras que en las dos muestras de Olmos de Atapuerca se observa fundamentalmente la presencia de hematites $\left(\mathrm{Fe}_{2} \mathrm{O}_{3}\right)$, en la de Barbadillo se ha detectado una mezcla de goethita $(\mathrm{FeO}(\mathrm{OH}))$, calcopirita $\left(\mathrm{CuFeS}_{2}\right)$ y hematites, siendo el primero de ellos más abundante.

Para llevar a cabo una comparación más precisa con la muestra del zoomorfo se llevaron a cabo análisis en el M.E.B. Así se aprecian pequeñas diferencias químicas que están relacionadas con la asociación mineral de cada una de ellas. El hierro $(\mathrm{Fe})$ es el elemento mayoritario en todas ellas, observándose también elementos como el Mn y el Ti que frecuentemente sustituyen al $\mathrm{Fe}$ en minerales como la hematites y la goethita, tal y como ocu-

no $\left(\mathrm{C}_{31} \mathrm{H}_{64}\right)$ (Heilbron et alii, 1934; Heilbron et alii 1935); además, en el alga roja Chondrus oscellatus se ha hallado el también n-alcano pentacosano $\left(\mathrm{C}_{25} \mathrm{H}_{52}\right)$ (Mori, 1943). Las algas pueden hallarse no sólo en estado independiente, sino también formando parte integrante de los líquenes, asociación simbiótica -generalmente terrestre y que puede ser reversible- entre una especie de hongos y otra de algas, siendo los líquenes más frecuentes los formados por un hongo ascomicete y un alga clorofícea (géneros Trebouxia, Myrmecia, Phycopeltis, etc.) (Margalef, 1977). rre en la muestra de Barbadillo. Otros elementos como $\mathrm{Ca}, \mathrm{Si}, \mathrm{Al}, \mathrm{Mg}$ y $\mathrm{K}$ que también son detectados en alguna muestra corresponden a la roca donde se forman los minerales de hierro. En todos los casos la composición química está en buen acuerdo con la mineralogía obtenida por difracción de rayos $\mathrm{X}$.

De acuerdo con los resultados obtenidos se observa una alta similitud entre la muestra del caballo y las de Olmos de Atapuerca (a unos 4 km de distancia de Cueva Mayor), pareciendo así probable que la materia prima se obtuviera de la propia Sierra deAtapuerca.

\section{PROBLEMÁTICA EN TORNO A LA CRONOLOGÍA}

Desde los orígenes del conocimiento de la expresión gráfica rupestre paleolítica, en 1879 en la Cueva de Altámira de la mano de Marcelino Sanz de Sautuola, las polémicas en torno a lo que viene denominándose autentificación, o en otros términos cronología paleolítica o contemporánea (6), no han parado de sucederse. Más aún, en la actualidad continúa siendo uno de los temas más espinosos y problemáticos, unas veces olvidado otras obviado. Los elementos de la argumentación vienen a presentarse casi invariables desde los inicios de la investigación. Solamente la incorporación de nuevas variables venidas de la introducción de analíticas ha intentado, en algunos casos, mostrarse como elemento definitorio y sentenciador en la resolución de la cuestión. A pesar de ello, hasta la actualidad, "la certificación estratigráfica aportada por un depósito geológico es la única evidencia que asegura, per se, la antigüedad de una representación del arte paleolítico, como término de referencia ante quem de la realización de esa obra" (Barandiarán, 1995: 39).

El tema de la autentificación de las grafías rupestres no será ajeno a la presente figura. Los argumentos que se venían manejando para la certificación prehistórica del arte rupestre se apoyaban en criterios circunstanciales al hallazgo y en la opinión de una o varias autoridades en la materia que acreditaban, a partir de su experiencia, la antigüedad del mismo.

(6) Se entiende por este concepto una de las acepciones que muestra, referido a cuestiones históricas, el Diccionario de la Lengua Española de la Real Academia Española: "Relativo al tiempo o época actual". 


\section{Las dudas en torno a la certificación paleolítica y la opinión del $\mathrm{H}$. Breuil}

Ya desde la primera publicación, J. Carballo (1910: 472) duda de la edad prehistórica de la cabeza de caballo, para cuya justificación relata la experimentación llevada a cabo por él con relación a la Cueva deAltamira, exponiendo la dificultad de conservación de una pintura sujeta a las condiciones atmosféricas externas (principalmente, según él, la luz y el agua).

Sin embargo, años después, H. Breuil (1920: 331) atribuyó dicha pintura a un periodo antiguo del Paleolítico Superior comparándola con las figuras de Covalanas y La Haza, lo que de hecho supuso la autentificación de la pintura ante los prehistoriadores.

No obstante el geólogo J. Royo y Gómez (1926: 64) indicaba, taxativamente, que "aunque se ha señalado en ella la existencia de pinturas y grabados prehistóricos, en realidad se trata de figuras modernas o meramente casuales, y así en el lugar en que se había indicado una cabeza de oso en rojo, se ve una cabeza muy tosca de caballo y completamente actual".

Siguiendo la opinión de Breuil, otros investigadores han defendido su cronología paleolítica, desde el Auriñaciense (Martínez Santa-Olalla, 1925: 168) hasta el Magdaleniense inferior (Jordá, 1964: 68; Corchón et alii, 1988-89: 14). Otros autores ven difícil matizar su edad más allá del genérico calificativo de paleolítica (Balbín y Alcolea, 1994: 132).

\section{El contexto externo: argumentos ambientales y gráficos}

El panorama contextual dentro de la provincia de Burgos se presenta reducido tanto en evidencias como en estudios referidos al Paleolítico Superior, debido a la inexistencia de proyectos de investigación, a lo que debiera añadirse que, en la mayor parte de los casos, se trata de investigaciones de principios de siglo con la problemática que ello conlleva. El conjunto de materiales arqueológicos procede de las cuevas del Caballón, de La Blanca y otras de la zona de Oña y alrededores (Ibero, 1923: 174-195; García Soto 1988: 20-32), la Cueva de Peñacoba (Martínez Santa-Olalla, 1925: 164) y la Cueva de LaAceña (Breuil y Obermaier, 1913: 1415), estando en la actualidad la mayor parte de los materiales en paradero desconocido. Una datación de $\mathrm{C}^{14}$ de $15600 \pm 230$ B.P. pone de manifiesto el tránsito por el interior del Complejo de Ojo Guareña durante el Paleolítico Superior (Delibrias et alii, 1974: 53).

Las evidencias gráficas se presentan también escasas. Sobre un soporte mueble de la Cueva del Caballón (Ibero, 1923: 184; García Soto, 1988: 23 29) se encuentra la única evidencia, actualmente en paradero desconocido, localizada hasta el presente en la provincia de Burgos. Evidencias rupestres se encuentran en la Cueva de Penches (Hernández Pacheco, 1917; Ripoll y G. E. Edelweiss, 1957) y en el Complejo Kárstico de Ojo Guareña (Ortega y Martín, 1986: 331-389; Corchón et alii, 1997).

El Sistema Cueva Mayor-Cueva del Silo se sitúa a una altitud de 1036 m.s.n.m, muy superior a la que se localizan las estaciones rupestres de la Cornisa Cantábrica, siendo la de mayor altitud la Cueva de Los Santos o del Becerral (Cantabria) (Bernaldo de Quirós et alii, 1988-1989), a 720 m, junto a la morrena terminal del glaciar de Bustalveinte, siendo éste uno de los argumentos esgrimidos (7), por parte de C. González Sainz (González Echegaray y González Sainz, 1994: 34), para tomar con precaución su asignación paleolítica. No obstante, el panorama cantábrico contrasta con el burgalés: la Cueva de Penches (Barcina de los Montes, Burgos) se enclava a $767 \mathrm{~m}$ y la Cueva Palomera del Complejo de Ojo Guareña (Burgos) a $730 \mathrm{~m}$, ambas en la Cuenca del Ebro y cercanas a la divisoria con Cantabria. De hecho existen dataciones radiocarbónicas directas para las pinturas de la Sala de las Pinturas de Ojo Guareña que oscilan entre $10950 \pm$ 100 y $11540 \pm 100$ B.P. (Corchón et alii, 1997).

Debe tenerse presente que el Portalón de Cueva Mayor se localiza en una latitud sensiblemente más meridional que las anteriores y a su vez, más septentrional que otras cavidades que presentan una altitud similar como la Cueva de la Griega de Pedraza (Segovia) a 1020 m (Corchón, 1997), la Cueva

(7) A parte de la situación y altitud también fueron tenidos en cuenta otros criterios: "ausencia de restos de ocupación paleolítica" reconocidos hasta la actualidad, "escasas posibilidades de conservación de pintura en la cueva debido a las fuertes corrientes de aire y gelifracción que aún en la actualidad están afectando a su parte anterior", realización del diseño por encima de pequeños espeleotemas, existencia de una tradición espeleológica que no se refiere a las grafías, dificultades en el establecimiento de una "homologación automática" en unos de los caballos, considerado por González Sáinz como "única representación figurativa segura" y "existencia de un extraño reborde blanquecino enmarcando el trazo de ese caballo" (González Echegaray y González Sáinz, 1994: 34).

T. P., 58, n. $^{\circ} 1,2001$ 
de la Hoz (Guadalajara) a $1050 \mathrm{~m}$ (Balbín et alii, 1995) o la Cueva del Turismo (Guadalajara) a 1090 m (Alcolea et alii, 1995).

La existencia de grabados en zonas exteriores, "paredes sobre las que incide directamente la luz. del sol, o están bien iluminadas en las zonas de antecueva hasta la penumbra" (Fortea, 1994: 203204), muestra una amplia dispersión tanto en la Cornisa Cantábrica como en otras localizaciones (Siega Verde (Balbín et alii, 1991), Domingo García (Ripoll y Municio, 1999), Foz Côa (Baptista y Gomes, 1997), Mazouco (Jorge et alii, 1982) y Fornols-Haut (Sacchi et alii, 1988)). Dejando a un lado la técnica del grabado, las localizaciones de pinturas en contextos exteriores son escasas (Fortea, 1994; Baptista, 1999: 154-157; Balbín y Alcolea, 1999).

La representación zoomorfa es una silueta de animal donde el formato elegido es la cabeza, señalándose para el caso concreto una serie de detalles anatómicos. La elección de formatos parciales, y en concreto la cabeza, es una constante en el arte paleolítico (Romero, 1986: 118). La categoría temática del équido es una de las más abundantes en la zona cantábrica junto a los cérvidos, bóvidos y cápridos (Moure, 1988: 83-84). No obstante, son pocos los yacimientos que poseen únicamente el caballo como representación figurativa: San Antonio en Asturias (Hernández Pacheco, 1919) y, en Cantabria, Sotarriza (San Miguel, 1986-1988) y Cullalvera (González Sainz et alii, 1997), todos en negro y con una situación en el espacio interior (zonas oscuras), destacando además por poseer los dos primeros una única representación. Técnicamente, la pintura y el grabado se asemejan en número de aparición en figuras de caballos, lo mismo que la preferencia por el color rojo y por el negro (Carayon, 1982: 18-22).

\section{Contexto interno de la cavidad}

El soporte se encuentra afectado por las influencias climáticas del exterior, en especial la condensación y la iluminación natural de manera indirecta, llegando los rayos solares sólo a los primeros metros de la cavidad, al localizarse ésta en el fondo de una pequeña depresión. Estos factores favorecen la existencia de unas condiciones de humedad y temperatura propicias para el desarrollo de organismos liquénicos. Una observación macroscópica detenida pone de manifiesto la superposición y puntual infraposición de estos organismos en relación a la pintura.

La pared en la que se localiza la pintura es un plano de fractura. Por otra parte, la bóveda y paredes del Portalón se han visto afectadas por fenómenos crioclásticos, desprendiéndose progresivamente en forma de clastos de tamaño variable que han ido engrosando los diferentes niveles arqueo-estratigráficos, como pudo comprobarse en la excavación de J.M. Apellániz, en la que los grandes bloques caídos del techo aparecían de forma habitual. Este proceso se ha visto favorecido por la influencia climática del exterior, ya que tan sólo a unas decenas de metros del Portalón, donde las variaciones climáticas no son tan notorias, se comienzan a observar las familiares formas redondeadas de los conductos, debidas a su disolución bajo condiciones freáticas, que indican que sus paredes han permanecido inalteradas desde la formación del conducto, sin apenas haberse visto afectadas por desconchados ni caídas de bloques.

El contexto arqueológico más inmediato a la representación estudiada es la existencia de una importante secuencia estratigráfica puesta de manifiesto por la excavación de J.M. Apellániz, apenas a $3 \mathrm{~m}$ del caballo, que abarca desde la Edad Media hasta el Bronce Antiguo, localizándose este último a una profundidad de $2.5 \mathrm{~m}$ en relación con la superficie actual. En otro sector del Portalón Clark (1979: 94-97) puso al descubierto niveles eneolíticos, y en la Galería del Sílex se evidencian una ocupación neolítica y otra de la Edad del Bronce (Apellániz y Uribarri, 1976; Apellániz y Domingo, 1987). Por otra parte, actuales prospecciones geofísicas han puesto de manifiesto que el relleno estratigráfico del Portalón alcanza, al menos, los $8 \mathrm{~m}$ de profundidad.

Otra de las cuestiones a destacar es la relación existente entre las grafías y el suelo actual (Fig. 4). La representación figurativa se sitúa a una distancia de aquel comprendida entre 1.14 y $1.77 \mathrm{~m}$. Considerando que el nivel arqueológico más profundo excavado por Apellániz (Bronce antiguo) se encuentra a una cota inferior en $3.6 \mathrm{~m}$ respecto del caballo y que presenta un buzamiento mayor de $20^{\circ}$ (Fig. 4B, sección 1) (siendo la pendiente media de la rampa de entrada a la cavidad de $25^{\circ}$ ), los posibles niveles superopaleolíticos debieran de localizarse muy por debajo del nivel del suelo y por tanto del caballo, máxime si se tiene en cuenta que la aparente horizontalidad del actual suelo del Portalón comenzó a fraguarse en un momento indetermi- 

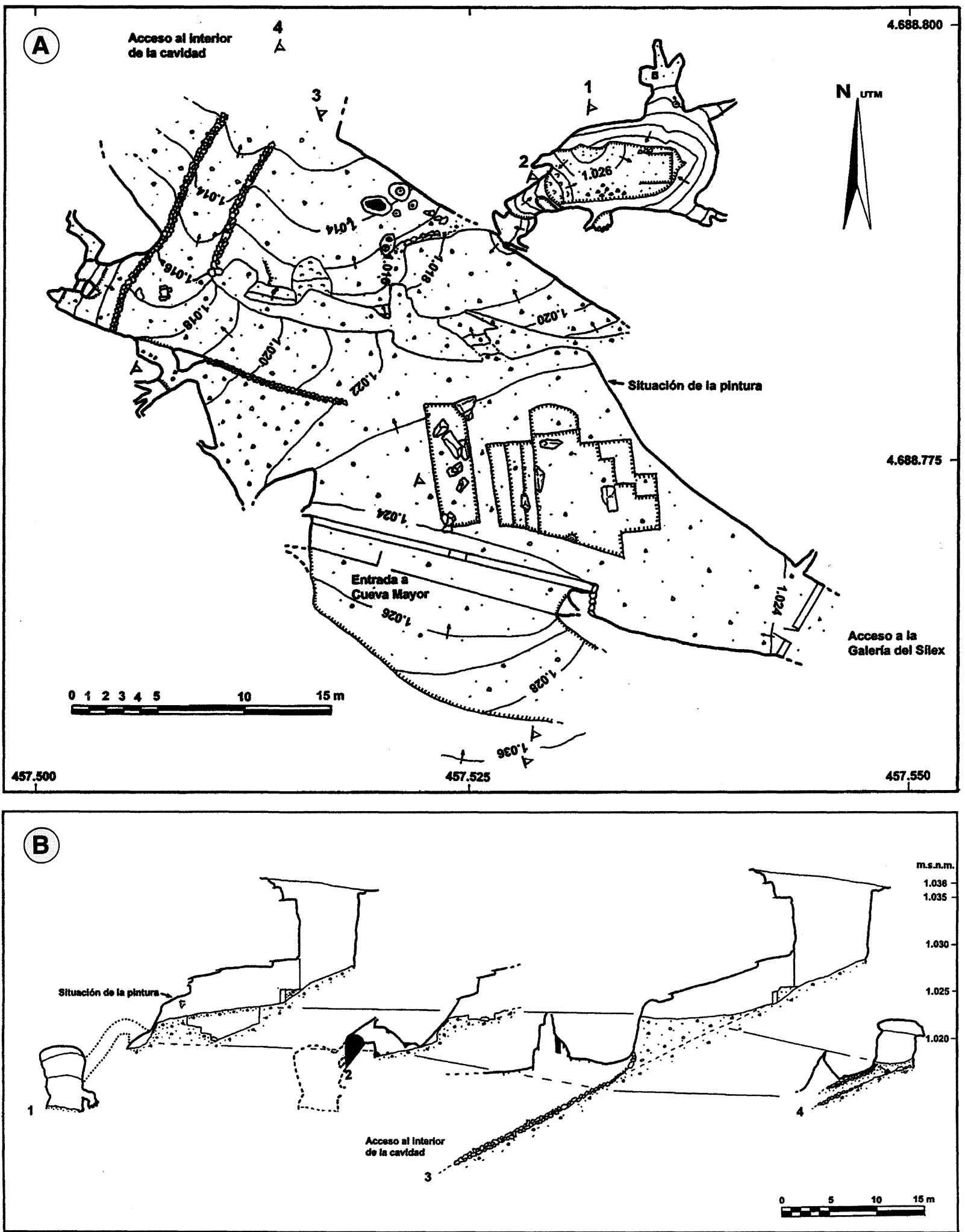

Fig. 4. Portalón de Cueva Mayor (Ibeas de Juarros, Burgos): planta (A) y secciones transversales (B). Topografía del Grupo Espeleológico Edelweiss.

T. P., 58, n. $^{\circ} 1,2001$ 
nado de la Edad del Bronce, cuando los sucesivos aportes sedimentarios provocaron que la rampa original de acceso al interior de la cavidad llegara a tocar un sector de bóveda baja (al SE de la misma), motivando su rápida colmatación y, por tanto, el inicio de su tendencia hacia la horizontalidad actual (Fig. 4B, sección 2).

Lógicamente, dicho proceso se vio acompañado por una alteración de la dirección de la rampa, dado que los aportes sedimentarios que rodaban hacia el interior de la cavidad comenzaron a bordear el sector que se estaba colmatando, hasta modificar por completo la morfología de la galería de acceso, pasando de adoptar una morfología de hemicono, con pendiente monoclinal y dirección similar a la del eje de la galería, a otra en la que en sus primeros metros la dirección y pendiente de la rampa se adaptaron (Fig. 4A) hasta salvar el obstáculo recién formado (la colmatación del sector de bóveda baja), para finalmente, una vez superado, continuar con la deposición de materiales en la parte media y baja del cono.

En el interior de la cavidad no se conoce ninguna evidencia artística, arqueológica o paleontológica que encaje inexcusablemente en momentos del Paleolítico Superior, mientras que, por el contrario, son abundantes los restos fósiles del Pleistoceno Medio asociados a antiguas entradas hoy totalmente colmatadas, así como los indicios claramente postpaleolíticos: muestras de arte rupestre, inhumaciones, restos cerámicos y líticos, silos, presas, etc.

Tan sólo los niveles inferiores del cono de derrubios formado en la entrada de Cueva Mayor podrían albergar niveles superopaleolíticos, y ello en el caso de que el hundimiento de la bóveda que propició la formación de la entrada actual tuviera al menos esa cronología y, en ese caso, si además el descenso al interior de la cueva fuera practicable, dado que el desnivel existente entre la superficie y la base del cono de derrubios es de $34 \mathrm{~m}$, que se reducen a 23 $\mathrm{m}$ si se considera la altura a la que se abre el zócalo de la puerta de entrada actual: en cualquier caso un desnivel bastante respetable.

\section{CONCLUSIONES}

Los argumentos anteriormente citados poseen diferente peso en la discusión relativa a la edad de la pintura. De este modo, la altitud a la que se abre la cueva no es determinante para discriminar la cronología de los motivos debido a la existencia de otras cavidades a cotas similares. Si bien son escasas las referencias a contextos arqueológicos del Paleolítico Superior en la provincia de Burgos, éstas se reparten por todo el ámbito burgalés; es muy probable que futuras prospecciones sistemáticas mostraran una mayor intensidad de hallazgos.

La búsqueda de paralelos gráficos tampoco aporta elementos de juicio definitivos para solventar la problemática que aquí nos ocupa.

En los análisis practicados no se han encontrado materiales extraños que pudieran hacer pensar en componentes anacrónicos a momentos paleolíticos. Más bien, los resultados de las analíticas efectuadas para la caracterización de la materia colorante se asemejan a conjuntos considerados de edad paleolítica (Clot et alii, 1995; Clottes et alii, 1990; Menu et alii, 1993, 1996), pero también a otro cuya cronología prehistórica ha sido puesta seriamente en duda (Menu y Walter, 1992). De este modo, el recurso al estudio de la composición del colorante en el proceso de datación de una obra presenta claros límites en su uso (8). Ante la presente situación debe reconocerse, para el caso concreto, que de poco sirven las analíticas. A su vez, se pudo concretar que la captación del mineral de hierro se llevó a cabo en una zona próxima a Cueva Mayor.

Es de destacar el interés que Sampayo y Zuaznávar, en 1868, muestran en la recolección de inscripciones, por lo que sorprende que una evidencia de color rojo, situada frente a la entrada y sobradamente iluminada no fuera señalada por éstos. También llama la atención que el guía que acompañó a L. March en 1906 conociera la existencia de unos presuntos grabados prehistóricos de pequeño tamaño localizados en un recóndito lugar de la cueva y no hubiera visto la cabeza de caballo. Ambas cosas hacen pensar que tal vez la pintura no existiera en 1906.

De hecho, a pesar de que el reconocimiento de la autenticidad del arte rupestre paleolítico era reciente, ya por aquellas fechas se tenía conocimiento de la existencia de falsificaciones, entre las que destaca la Cueva de Suances citada tanto por Carballo (1910) como por Breuil (1921) en sus artículos.

Ya se comentó que el Portalón de Cueva Mayor es un lugar suficientemente iluminado. Esta carac-

(8) "Los análisis de los colores publicados determinan si los pigmentos son naturales (y de entidad similar a los que usaban los paleolíticos) o producto moderno; pero no permiten normalmente decidir, cuando se trata de pigmentos naturales y preparados al estilo de los de la Prehistoria, si realmente fueron aplicados sobre la pared en aquel tiempo o, por un diestro imitador, hace poco" (Barandiarán, 1995: 40). 
terística es probable que haya influido en la conservación de la pintura. De hecho, en las fotografías publicadas por H. Breuil y H. Obermaier (1913: 5, fig. 3) y posteriormente por M. Almagro (1947: 373, fig. 293) se observa el motivo con mayor nitidez que en la actualidad. Resulta llamativo el rápido deterioro que ha sufrido la pintura en estos últimos 80 años. Si se valorara la pintura como de cronología paleolítica habría que aceptar distintos ritmos de alteración: en un mínimo de 11000 años apenas se alteró y en el pasado siglo el deterioro ha sido rápido.

Como se ha apuntado, la secuencia estratigráfica, así como el buzamiento que presentan los niveles inferiores hacen pensar en que los niveles del Paleolítico Superior, si es que existen, se localicen a cotas muy inferiores, tal y como puede intuirse de la observación de los niveles arqueológicos de la excavación de J.M. Apellániz.

Dado que en las galerías inferiores de Cueva Mayor existen a nivel superficial evidencias del Pleistoceno Medio (Ursus deningeri en posición anatómica asociados a yacijas y zarpazos en arcilla), debe descartarse la posibilidad de una reactivación hidrológica de la cavidad en momentos posteriores. Por otra parte la situación y morfología de la entrada de Cueva Mayor hacen muy poco probable la posibilidad de importantes reexcavaciones en momentos postpaleolíticos de los depósitos sedimentarios del Portalón, dado que los aportes de material distan mucho de las características propias de fenómenos de grandes avenidas. Por ello es improbable la existencia previa de niveles de finales del Paleolítico a cotas similares a las actuales. Por lo expuesto tampoco puede sostenerse la posibilidad de acceder desde un hipotético suelo paleolítico hasta el nivel de la pintura, debido a la configuración del suelo en pronunciada rampa y por la morfología extraplomada de la pared en que se localiza.

Respecto al hundimiento de la bóveda de la cavidad que propició la apertura de la actual entrada de Cueva Mayor, también se tienen serias dudas en cuanto a su cronología y accesibilidad, que tan sólo disipará una excavación en profundidad. Parece cuando menos extraño que se produzca un importante hiatus entre los restos pleistocenos, asociados a antiguas entradas y conservados sin apenas alteraciones, y los abundantes restos postpaleolíticos localizados por todos los rincones de la cavidad.

Por todo ello no pensamos, en la actualidad, que pueda mantenerse una cronología paleolítica para la pintura estudiada, siendo probable que se trate de un diseño realizado a principios del actual siglo $X X$. En este contexto no debe extrañar el hecho de que la materia colorante sea hematites, dado que por aquella época también se hacían experimentaciones con óxidos naturales, y el propio Carballo (1910: 470-471) cita detalladamente las que él mismo venía realizando con ese mismo componente, precisamente para comprobar las diferencias de conservación entre un ambiente húmedo y oscuro, y otro seco y luminoso.

De todas formas sería conveniente la realización de una excavación con la que se contrastase la posible existencia de niveles del Paleolítico Superior, así como, en su caso, la cota a la que apareciesen.

\section{AGRADECIMIENTOS}

Este trabajo ha sido financiado por el Ministerio de Educación y Ciencia (Proyecto Investigación de Atapuerca PB93-0066) y por la Junta de Castilla y León (para la realización de los trabajos de campo). Deseamos agradecer el tiempo dedicado por algunos de los componentes del Equipo de Investigación de Atapuerca con quienes se ha debatido e intercambiado opiniones. También queremos agradecer a Sandra Silvestre su ayuda técnica en la realización de la CG/EM. Por último, debemos agradecer a la empresa Iberdrola su apoyo y colaboración con la dotación de una Beca de Formación de Personal Investigador aAna I. Ortega Martínez.

\section{BIBLIOGRAFÍA}

Aguirre, E.; Carbonell, E. y Bermúdez de Castro, J.M. (1987): El Hombre Fósil de Ibeas y el Pleistoceno de la Sierra de Atapuerca. Junta de Castilla y León.Valladolid.

Aguirre, E.; BAsAbÉ, J.M. y ToRres, T.J. (1976): "Los fósiles humanos deAtapuerca (Burgos): nota preliminar". Zephyrus, 26-27: 452-489.

Alcolea, J.J.; Balbín, R. de; García, M.A. y Cruz, L.A. (1995): "La cueva del Turismo (Tamajón, Guadalajara): un nuevo yacimiento rupestre paleolítico en la meseta castellana". En R. de Balbín, J. Valiente y M.T. Musat (eds.): Arqueología en Guadalajara. Patrimonio Histórico-Arqueología Castilla-La Mancha. Guadalajara: $125-136$.

Almagro Basch, M. (1947): “El Paleolítico Español”. En R. Menéndez Pidal (dir.): Historia de España. I, España Prehistórica, I. Espasa Calpe. Madrid: 443-485.

ApellánIz, J.M. y Domingo, S. (1987): Estudios sobre Ata-

T. P., 58, n. $^{\circ} 1,2001$ 
puerca (Burgos) II. Los materiales de superficie del Santuario de la Galería del Sílex. Cuadernos de Arqueología de Deusto, 10. Servicio de Publicaciones de la Universidad de Deusto. Bilbao.

Apellániz, J.M. y URIBARRI, J.L. (1976): Estudios sobre Atapuerca (Burgos) I. El Santuario de la Galería del Sílex. Cuadernos de Arqueología de Deusto, 5. Bilbao.

BALBín, R. de (1989): "L'art de la grotte de Tito Bustillo (Ribadesella, Espagne). Une vision de synthèse". L'Anthropologie, 93, 2: 435-462.

Balbín, R. de y Alcolea GonzÁlez, J.J. (1994): “Arte Paleolítico de la Meseta Española”. Complutum, 5: $97-$ 138.

- (1999): "Vie quotidienne et vie religieuse. Les sanctuaires dans l'art paléolithique". L'Anthropologie, 103, 1: 23-49.

Balbín, R. de; Alcolea, J.J.; Cruz, L.A. y Moreno, F. (1995): "Investigaciones arqueológicas en la cueva de la Hoz (Santa María del Espino, Guadalajara). Una visión de conjunto actualizada". En R. de Balbín, J. Valiente y M.T. Musat (eds.): Arqueología en Guadalajara. Patrimonio Histórico-Arqueología Castilla-La Mancha. Guadalajara: 37-54.

Balbín, R. de; Alcolea, J.J. y SAntonja, M. (1991): "Siega Verde (Salamanca). Yacimiento artístico paleolítico al aire libre". Del Paleolítico a la Historia. Museo de Salamanca. Salamanca: 33-48.

Balbín, R. de y GonzÁlez Sainz, C. (1993): "Nuevas investigaciones en la cueva de La Pasiega (Puente Viesgo, Cantabria)". Boletín del Seminario de Estudios deArte y Arqueología, LIX: 9-34.

Baptista, A. M. (1999): No tempo sem tempo. A arte dos caçadores paleolíticos do Vale do Côa. Parque Arqueológico Vale do Côa. Vila Nova de Foz Côa.

BAPTISTA, A.M. y GoMEs, M.V. (1997): “Arte rupestre”. En J. Zilhão (coord.): Arte Rupestre y Pré-história do Vale do Côa. Ministério da Cultura. Lisboa: 213-406.

BARANDIARÁN, I. (1995): "La datación de la gráfica rupestre de apariencia paleolítica: un siglo de conjeturas y datos". Veleia, 12: 7-48.

Bermúdez, J.M.; Arsuaga, J.L.; Carbonell, E. y RodríGUEZ, J. (ed.) (1999): Atapuerca. Nuestros antecesores. Catálogo de la exposiciónAtapuerca. Nuestros antecesores. Fundación del Patrimonio de Castilla y León. Madrid.

BERnALdo de Quirós, F.; Bohigas, R. y CABRERA, V. (19881989): "Las pinturas rupestres de la cueva de Los Santos o del Becerral (Cantabria)". Ars Praehistorica, VIIVIII: 87-96.

Bosch, F. (1996): Las técnicas analíticas aplicadas al estudio de las obras de arte. Discurso leído en la solemne apertura del curso 1996-1997. Servei de Publicacions de la Universitat de València. Valencia.

Brassell, S.C.; Eglinton, G.; Maxwell, J.R. y PhilP, R.P. (1978): "Natural background of alkanes in the aquatic environment". En O.L.H. Hutzinger, L.H. Van Lelyveld y B.C.J. Zoeteman (eds.): Aquatic pollutants: Transformation and biological effects. Pergamon Press. Oxford: 69-86.

Breuil, H. (1920): “Miscellanea d'Art Rupestre (1)". Boletín de la Real Sociedad Española de Historia Natural, XX: 322-333.

- (1921): "Rectificación que remite el abate Henri Breuil con motivo de una nota del Sr. Carballo". Boletín de la Real Sociedad Española de Historia Natural, XXI: 269-271.

- (1934): Les peintures schematiques de la Península Iberique, 1. Au nord de Tage. Foundation Singer Polignac. Lagny.

- (1952): 400 Siécles d’Art Pariétal. Les cavernes ornées de l'age du Renne. Max Fourny. Paris.

Breuil, H. y Obermaier, H. (1913): "Institut de Paléontologie Humaine. Travaux exécutés en 1912". L'Anthropologie, XXIV: 1-16.

CABRÉ, J. (1915): ElArte Rupestre en España. Memorias de la Comisión de Investigaciones Paleontológicas y Prehistóricas, 1. Madrid.

Carayon, M. (1982): "Les équidés de l'art parietal paleolithique du'nord de l'Espagne". Travaux de l'Institut d'Art Prehistorique, XXIV: 1-57.

Carballo, J. (1910): "De Espeleología”. Boletín de la Real Sociedad Española de Historia Natural, X: 468-481.

- (1921): "Las cuevas de Atapuerca y San García (Burgos)". Boletín de la Real Sociedad de Historia Natural, XXI: $138-141$.

ClARK, G.A. (ed.) (1979): The North Burgos Archeological Survey. Bronze and IronAge Archaeology on the Meseta del Norte (Province of Burgos, North-Central Spain). Arizona State University. Dept. of Anthropology. Anthropological Research Papers 19. Tempe. Arizona.

Clot, A.; Menu, M. y Walter, Ph. (1995): "Manières de peindre des mains à gargas et Tibiran (Hautes-Pyrénées)". L'Anthropologie, 99, 2/3: 221-235.

Clottes, J.; Menu, M. y Walter, Ph. (1990): “La préparation des peintures magdaléniennes des cavernes ariégeoises". Bulletin de la Societé Préhistorique Française, 87, 6: 170-192.

Corchón, S. (coord.) (1997): La cueva de La Griega de Pedraza (Segovia). Memorias deArqueología en Castilla y León, 3. Junta de Castilla y León. Zamora.

Corchón, S.; LuCAS, R.; GonzÁlez-TABlas, F.J. y BÉcares, J. (1988-89): "El arte rupestre prehistórico en la región Castellano-Leonesa (España)". Zephyrus, XLI-XLII: 7-18.

Corchón, S.; Valladas, M.; Becares, J.; Arnold, M.; TisNERAT, N. y CAHIER, H. (1997): "Datación de las pinturas y revisión del arte paleolítico de Cueva Palomera (Ojo Guareña, Burgos, España)".'Zephyrus, 49 (1996): 37-60.

Delibrias, G.; Guillier, M.T. y Labeyrie, J. (1974): “Grif Radiocarbon Measurements VIII”. Radiocarbon, 16 53. 
EvERSHED, R.P. (1993): "Biomolecular archaeology and lipids". WorldArchaeology, 25: 74-93.

ForTEA, J. (1994): "Los santuarios exteriores en el Paleolítico cantábrico". Complutum, 5: 203-220.

García Soto, E. (1988): "Materiales Paleolíticos (Colecciones de Saturio González y José M $^{\mathrm{a}}$ Ibero)". En G. Delibes, A. Esparza, E. García, J.R. López y M. Mariné: La colección arqueológica del Padre Saturio González en Santo Domingo de Silos. Excma. Diputación Provincial. Burgos: 9-32.

González Echegaray, J. y González Sáinz, C. (1994): "Conjuntos rupestres paleolíticos de la Cornisa Cantábrica". Complutum, 5: 21-43.

González Sainz, C.; MuÑoz, E. y Morlote, J.M. (1997): "De nuevo en La Cullalvera (Ramales, Cantabria). Una revisión de su conjunto rupestre paleolítico". Veleia, 14: 73-100.

HeIlbron, I.M.; PARry, E.G. y PhiPers, R.F. (1935): “The algae II. The relationship between certain algal constituents". Biochemical Journal, 29: 1376-1381.

HeIlbron, I.M.; PhIPERs, R.F. y Wright, H.R. (1934): “The chemistry of the algae, Part I. The algal sterol fucosterol". Journal of the Chemical Society, 136: 1572-1576.

Hernández PACHeCo, E. (1917): Los grabados de la Cueva de Penches. Memorias de la Comisión de Investigaciones Paleontológicas y Prehistóricas, 17. Madrid.

- (1919): La caverna de la Peña de Candamo (Asturias). Memorias de la Comisión de Investigaciones Paleontológicas y Prehistóricas, 29. Madrid.

IBERo, J.M. (1923): "El paleolítico de Oña y sus alrededores (Burgos)". Razón y Fe, 67: 171-194.

I.T.G.E. (1997): Mapa Geológico de España. Memoria de la hoja 200 (19/10). Burgos. Escala 1:50.000. Ministerio de Medio Ambiente. Madrid.

JORDA, F. (1964): "El arte rupestre paleolítico de la región cantábrica: nueva secuencia cronológica-cultural". Prehistoric Art of Western Mediterranean and Saharan (Wartenstein, 1960): 47-81. Barcelona.

- (1965): "Notas sobre la Trinchera de Atapuerca". Zephyrus, XVI: 149.

- (1985): "Los grabados de Mazouco, los santuarios monotemáticos y los animales dominantes en el arte Paleolítico peninsular". Revista de Guimaráes, XCIV: $1-23$.

Jorge, S.O.; Jorge, V.O.; Almeida, C.A.F.; SAnches, M.J. y SoEIRo, M.T. (1982): "Descoberta de gravuras rupestres em Mazouco, Freixo de Espada-à-Cinta (Portugal)".'Zephyrus, XXXIV-XXXV: 97-123.

MARCH, L. (1906): "Crónicas burgalesas. Las grutas de Atapuerca". Diario de Burgos, sábado 1 de septiembre: 1-2.

Margalef, R. (1977): Ecología. Omega. Barcelona.

Martín, M.A.; Domingo, S. y Antón, T. (1981): "Estudio de las cavidades de la zona BU-IV-A (Sierra de Atapuerca)". Kaite, Estudios de Espeleología Burgalesa, 2: 41-76.

T. P., 58, n. $^{\circ} 1,2001$
Martínez Santa-Olalla, J. (1925): "Prehistoria Burgalesa". Butlletí de l'Associació catalana d'Antropologia, Etnologia, Prehistoria, III, 2: 147-172.

- (1926): "Prehistoria Burgalesa. Neolítico y Eneolítico". Butlletí de l'Associació Catalana d'Antropologia, Etnologia, Prehistoria, IV: 85-109.

- (1930): "Cerámica incisa y cerámica de la cultura del vaso campaniforme en Castilla la Vieja y Asturias". Anuario de Prehistoria Madrileña, I: 99-129.

Meinschein, W.G. (1969): "Hydrocarbons - Saturated, Unsaturated and Aromatic". En G. Eglinton, G. y M.T.J. Murphy (eds.): Organic geochemistry: Methods and results. Springer-Verlag. Berlin: 330-356.

MELÉNDEZ, B. (1956): "Las pinturas rupestres como documentos paleontológicos". IV Congreso Internacional de Ciencias Prehistóricas y Protohistóricas (Madrid, 1954): 277-286. Zaragoza.

Menu, M. y Walter, Ph. (1992): "Análisis de la materia pictórica”. En J. Altuna, J.M. Apellániz e I. Barandiarán: Estudio de las pinturas de Zubialde (Álava). Resumen de los resultados. Diputación Foral de Álava. Vitoria: 61-64.

- (1996): "Les rythmes de l'art préhistorique". Techne, 3: 11-23.

Menu, M.; Walter, Ph.; Vigears, D. y Clottes, J. (1993): "Façons de peindre au Magdalenien". Bulletin de la Société Prehistorique Française, 90, 6: 426-432

MoRI, T. (1943): "The mucilage from Rhodophyceae".Journal of the Agricultural Chemical Society of Japan, 19: 297-300.

Moure, A. (1988): “Composition et variabilité dans l'art pariétal paléolithique cantabrique". L'Anthropologie, 92, 1: 73-86.

Obermaier, H. (1916): El Hombre Fósil. Memorias de la Comisión de Investigaciones Paleontológicas y Prehistóricas, 9. Madrid.

- (1925): El Hombre Fósil. Memorias de la Comisión de Investigaciones Paleontológicas y Prehistóricas, 9. Madrid, $2 .^{a}$ ed.

OrtegA, A.I. y Martín, M.A. (1986): "La Arqueología del Karst de Ojo Guareña”. En Grupo Espeleológico Edelweiss (ed.): Monografía sobre Ojo Guareña. Kaite, Estudios de Espeleología Burgalesa, 4-5: 331-389.

OsABA, B. (1965): “Objetos recientemente ingresados en el Museo". Boletín de la Institución Fernán González, 172: 126-128.

- (1979): "Las cuevas prehistóricas burgalesas en relación con el Museo Arqueológico", Kaite, Estudios de Espeleología Burgalesa, 1 (1978): 71-82.

PAlET, A. (1997): Identificación química de pigmentos artísticos. Col. Textos docents, 87. Universidad de Barcelona 14. Barcelona.

Pérez-González, A.; Aleixandre, T.; Pinilla, A.; Gallardo, J.; Benayas, J.; Martínez, M.J. y Ortega, A.I. (1995): "Aproximación a la estratigrafía de Galería en la Trinchera de la Sierra de Atapuerca (Burgos)". En 
J.M. Bermúdez de Castro, J.L.Arsuaga y E. Carbonell: Evolución Humana en Europa y los Yacimientos de la Sierra deAtapuerca (Jornadas Científicas Castillo de la Mota, Valladolid, 1992), I. Junta de Castilla y León. Valladolid: 99-122.

Perrodom, A. (1988): "Hydrocarbons". En E.A. Beaumont y N.H. Foster: Treatise of Petroleum Geology . Reprint Series, 8. Tulsa. Oklahoma: 3-26.

Puig y Larraz, G. (1896): Cavernas y Simas de España. Boletín de la Comisión del Mapa Geológico XXI. Madrid.

RIPOLL LóPEZ, S. (1997): “Algunas reflexiones en torno al arte paleolítico más meridional de Europa". Préhistoire Européenne, 10: 127-150.

Ripoll López, S. y Municio, L.J. (dirs.) (1999): Domingo García. Arte rupestre paleolítico al aire libre en la meseta castellana. Memorias de Arqueología en Castilla y León, 8. Junta de Castilla y León. Salamanca.

Ripoll Perelló, E. y G.E. Edelweiss (1957): "Revisión de la Cueva de Penches". IV Congreso Nacional de Arqueología (Burgos, 1955): 57-58. Zaragoza.
Romero, G. (1986): "El caballo en el arte rupestre paleolítico". Estudios de arte paleolítico. Centro de Investigación y Museo deAltamira, Monografías, 16. Ministerio de Cultura. Madrid: 67-132.

Royo y Gómez, J. (1926): Terciario continental de Burgos. XIV Congreso Geológico Internacional. ExcursiónA6. Instituto Geológico de España. Madrid.

Ruiz Zarzosa, V. y Martínez Arroyo, A. (1910): “Alhaja prehistórica de la provincia. La cueva de Ibeas y el P. Carballo". Diario de Burgos, miércoles 3 de agosto: $1-2$.

Sacchi, D.; Abelanet, J.; Brule, J.L.; Massiac, Y.; RubieLla, C. y ViletTe, Ph. (1988): "Les gravures rupestres de Fornols-Haut, Pyrénées-orientales". L'Anthropologie, 92, 1: 87-100.

SAMPAYO, P. y ZuAZnAVAR, M. (1868): Descripción con planos de la Cueva llamada de Atapuerca. Reproducido en Kaite, Estudios de Espeleología Burgalesa, 2 (1981): 7-40.

SAn Miguel, C. (1986-1988): "La Cueva Sotarriza-Covanegra". Sautuola, V: 47-54. 